\title{
Individual Variations in Sickness Absence
}

\author{
P. J. TAYLOR \\ From Shell U.K. Limited, Shell Haven, Essex
}

Records of personal sickness absence, including all spells of one day's duration or more, have been kept at this refinery for more than 20 years. The distributions of sickness spells and also calendar days of absence have been analysed for single years and also for periods of up to 20 years' continuous service for the I,350 hourly paid male employees. It is shown that both these measures of sickness absence are distributed among the men in an unequal fashion (negative binomial) rather than at random (Poisson) and thus resemble the distribution of industrial accidents first described almost 50 years ago. This pattern of distribution is not related to occupation or to length of service. Analysis of the distribution of lateness and absenteeism for reasons other than sickness or holidays shows that these also follow this pattern. It is postulated that this could be a principle applicable to all forms of industrial absenteeism as well as to accidents.

The personal records of 187 men with continuous service from 1946 to 1965 have been studied to investigate the trends in their sickness absence over this 20 -year period. In contrast to the well-recognized pattern that in any one period of time young men have more spells of absence than their older fellows, this secular study shows that sickness spells have not decreased with age. This apparent paradox is explicable by the rising national trend in sickness absence and by a high labour turnover in young men with frequent sickness spells.

Despite extensive study of sickness absence and its related problems in this country there are still gaps in our knowledge of the subject. The observations that women in industry have more sickness absence than men and that, while older workers have longer spells than the younger employees, the latter have more frequent short spells were first made in the Health of Munition Workers Committee Reports (1917, 1918) and later in some of the reports of the Industrial Fatigue Research Board.

Since the last war such patterns have been confirmed in the large-scale analyses of the London Transport Executive (1956) and in a number of other papers (Wyatt, 1945; Shepherd and Walker, 1957; Jones, 1959). The overall pattern of agerelated sickness absence rates in an industrial community is now so well known that some industrial physicians in this country have stopped keeping full sickness records on the grounds that the information is expensive to compile and of little practical value.

Sickness rates in industrial workers have shown a consistent rise in the United Kingdom since the

Received for publication January 3, 1967. war. Morris (1965) demonstrated that the national rate rose sharply some 10 years ago and this was associated with similar sharp rises in consumer expenditure, birth rate, and crime rates, thus suggesting some kind of social revolution. The development of more 'capital intensive' industries, which are required to run continuously at maximum capacity with relatively small work forces to remain economically viable, has made employers more sensitive to lost time and has thus accentuated the problem of sickness absence.

The detailed personal records kept at this refinery for many years have enabled some observations to be made on the overall distribution of sickness absence in male employees and also on its variation in individual men. This paper is concerned with the distribution of sickness absence in a community of male refinery workers and also with the secular changes in sickness absence frequency in a group of men continuously employed for 20 years.

The distribution of sickness absence between individual industrial workers has received little attention in the United Kingdom since two papers from Oxford were published almost 20 years ago (Russell, Whitwell, and Ryle, 1947; Sutherland and 
Whitwell, 1948). These showed that in one manufacturing company the annual spells of sickness absence were unevenly spread between the men and closely resembled the unequal chance (negative binomial) distribution first described for industrial accidents by Greenwood and Woods (1919). This type of distribution is quite different from that found when events occur by chance or at random when the Poisson distribution applies. A similar observation has been made by Hinkle and Wolff (1957) in the United States on employees of a telephone company.

The value of a study of the sickness absence records of individual men over a long period of time lies in the possibility that it may help to explain the well-known contrast in the sickness absence of young and older men. In all reports of industrial groups the frequency of sickness spells falls with increasing age when short spells are included in the figures. One might assume that men take fewer but longer spells of sickness as they grow older but only such a secular study can show whether this is true.

\section{Methods}

A sickness absence record card on which are recorded details of all absences of one day or more due to illness or injury is held by the medical department for each employee. The details include the dates of onset and return, the duration of the absence in calendar days, and the final diagnosis.

All hourly paid workers, with whom this paper is solely concerned, are required to punch their clock cards on arrival and departure from work. A weekly return is made to the accounts department who make out the wages sheets, and a copy goes to the medical department together with all medical certificates which provide the basic data for sickness absence recording.

A full-wage, sick-pay scheme has applied to all such workers for 20 years, and since this includes payment for single day absences these have always been recorded. The duration of benefit is related to the length of service; after six months an employee receives full pay for three weeks followed by half pay for two weeks. The duration of each benefit increases until the maximum benefit of 27 weeks full pay followed by 24 weeks at half pay is reached after I5 years' service. The full pay is made up after allowing for the Social Security benefit to which the employee is entitled. Thus a worker suffers no monetary loss whilst on his full sick-pay entitlement. No disciplinary action or dismissal has been enforced against men with a bad record of sickness absence during the years studied in this paper.
The population at risk for the purposes of this paper consists of the men employed throughout the year or years studied, thus excluding new employees and retirements. Thus analyses have been made on all men employed throughout one, Io and also 20 year periods. For this refinery the annual labour turnover has been usually 4 to $5 \%$, a rate much lower than that for British industry as a whole.

\section{Results}

Distribution of Sickness Absence in the Community The personal sickness record cards of all male hourly paid workers employed throughout 1964 were inspected and the number of spells of absence for each man is recorded in Table I. The

TABLE I

Spells of Sickness AbSence for Individual Men in 1964 with Expected Poisson and Negative Binomial DISTRIBUTIONS

\begin{tabular}{c|c|c|c}
$\begin{array}{c}\text { No. of } \\
\text { Absences }\end{array}$ & No. of Men & $\begin{array}{c}\text { Expected } \\
\text { Poisson }\end{array}$ & $\begin{array}{r}\text { Expected } \\
\text { Negative } \\
\text { Binomial }\end{array}$ \\
\hline 0 & 531 & $397 \cdot 7$ & $541 \cdot 0$ \\
1 & 409 & $486 \cdot 1$ & 379.6 \\
2 & 200 & 297.0 & 214.1 \\
3 & 93 & $121 \cdot 0$ & 110.9 \\
4 & 57 & 36.97 & 54.9 \\
5 & 38 & 9.03 & 26.4 \\
6 & 16 & 1.84 & 12.5 \\
7 & 2 & 0.32 & 5.8 \\
8 & 3 & 0.05 & 2.7 \\
9 & 0 & 0.01 & $1 \cdot 2$ \\
10 & 0 & - & 0.6 \\
11 & 1 & - & 0.3 \\
\hline Total & 1,350 & 1,350 & 1,350 \\
\hline
\end{tabular}

$\mathrm{n}=\mathrm{I}, 350 ;$ mean $=\mathrm{I} \cdot 223 ;$ standard deviation $=\mathrm{I} \cdot 460$

expected numbers of men for a chance or Poisson type of distribution and also for the unequal chance or negative binomial distribution were also calculated.

It can be seen from the Table that the negative binomial distribution provides a reasonable fit, but that the Poisson distribution is entirely different from that observed.

Similar analyses for the years 1962, 1963, and 1965 show that the pattern is consistent. For comparison, the results presented in Table II are given as the percentages of men having $0,1,2$, etc. spells of sickness absence rather than the numbers 
TABLE II

Percentages of Men having o, 1, 2, etc. Spells of SiCKNESS ABSENCE IN EACH YeAR, 1962-1965

\begin{tabular}{c|c|c|c|c}
\hline $\begin{array}{c}\text { No. of } \\
\text { Spells }\end{array}$ & 1962 & 1963 & 1964 & 1965 \\
\hline 0 & 36.2 & 34.3 & 39.4 & 35.0 \\
I & 27.5 & 29.8 & 30.3 & 27.2 \\
2 & 15.8 & 16.0 & 14.8 & 16.8 \\
3 & 9.3 & 8.9 & 6.9 & 10.4 \\
4 & 4.8 & 5.2 & 4.2 & 5.2 \\
5 & 3.1 & 2.8 & 2.8 & 2.8 \\
6 & 1.7 & 1.5 & 1.2 & 1.4 \\
7 & 0.7 & 0.6 & 0.1 & 0.8 \\
8 & 0.5 & 0.4 & 0.2 & 0.2 \\
9 & 0.3 & 0.2 & - & 0.2 \\
I0 & - & 0.1 & - & - \\
11 & - & 0.05 & 0.1 & - \\
I2 & 0.1 & 0.05 & - & - \\
13 & - & 0.05 & - & - \\
14 & - & - & - & - \\
15 & - & 0.05 & - & - \\
\hline Mean spells & 1.45 & 1.45 & 1.22 & 1.43 \\
Standard & 1.69 & 1.69 & 1.46 & 1.57 \\
deviation & 1.69 & & \\
\hline
\end{tabular}

of men since the numbers at risk for each year are not quite the same.

A consistent pattern can also be demonstrated for the annual duration of all sickness spells in individual men. This is illustrated in Table III, in which is recorded the number of men having 0-9, 10-19, 20-29, etc. total days of sickness absence in 1964 together with the numbers expected from a Poisson and a negative binomial distribution.

As in the previous measure of spells of absence, the observed distribution is somewhat similar to the negative binomial distribution but bears no resemblance to the Poisson distribution.

The consistency of this phenomenon over four single years is shown in Table IV. The long 'tail' of a few men each year with over 100 days of absence is combined in the Table for reasons of space. As in Table II, the percentage of men in each group is included rather than the observed number of men.

Such observations confirm those already mentioned that the distribution of sickness absence, whether measured in spells or days, is not random in any one year but resembles the pattern known to occur in accidents (Froggatt and Smiley, 1964). Further analysis is required to show the degree of association between the absences of the same individual in different years, and this will be included in a later paper.
The demonstration that a few men are responsible for a disproportionate amount of sickness is not in itself an argument for the theory of an unequal chance. As Arbous and Kerrich (I95I) explained in their review of the theory of accident proneness, the 'tail' of a normal distribution can account for

TABLE III

Calendar Days of Sickness Absence in Individual Men in 1964 with Expected Poisson and Negative Binomial DISTRIBUTIONS

\begin{tabular}{c|c|c|c}
\hline No. of Days & No. of Men & $\begin{array}{c}\text { Expected } \\
\text { Poisson }\end{array}$ & $\begin{array}{c}\text { Expected } \\
\text { Negative } \\
\text { Binomial }\end{array}$ \\
\hline $0-9$ & 821 & $228 \cdot 5$ & $859 \cdot 3$ \\
$10-19$ & 237 & $1,064 \cdot 5$ & $194 \cdot 2$ \\
$20-29$ & 124 & $57 \cdot 0$ & $103 \cdot 2$ \\
$30-39$ & 67 & 0 & $61 \cdot 9$ \\
$40-49$ & 34 & 0 & $38 \cdot 4$ \\
$50-59$ & 19 & 0 & $24 \cdot 8$ \\
$60-69$ & 14 & 0 & $16 \cdot 6$ \\
$70-79$ & 6 & 0 & $11 \cdot 2$ \\
$80-89$ & 7 & 0 & $7 \cdot 7$ \\
$90-99$ & 8 & 0 & $5 \cdot 3$ \\
& & 0 & $3 \cdot 7$ \\
$100-109$ & 5 & 0 & $2 \cdot 6$ \\
$110-119$ & 2 & 0 & $2 \cdot 0$ \\
$120-129$ & 1 & 0 & $1 \cdot 1$ \\
$130-139$ & 2 & 0 & $18 \cdot 0$ \\
over 140 & 2 & 1,350 & 1,350 \\
\hline Total & 1,350 & & 0 \\
\hline
\end{tabular}

$\mathrm{n}=1,360 ;$ mean $=12.96 ;$ standard deviation $=20.81$

\section{TABLE IV}

Percentages of Men having 0-9, 10-19, etc. Calendar Days OF SiCKNESS ABSENCE IN EACH YeAR, 1962-1965

\begin{tabular}{c|r|r|r|r}
\hline $\begin{array}{c}\text { No. of } \\
\text { Days }\end{array}$ & 1962 & 1963 & 1964 & 1965 \\
\hline $0-9$ & 58.3 & 57.2 & 61.0 & 60.8 \\
$10-19$ & 17.7 & 19.5 & 17.6 & 19.1 \\
$20-29$ & 10.2 & 9.3 & 9.2 & 8.2 \\
$30-39$ & 5.8 & 5.3 & 5.0 & 4.4 \\
$40-49$ & 2.6 & 2.5 & 2.5 & 3.0 \\
$50-59$ & 1.8 & 1.7 & 1.4 & 1.4 \\
$60-69$ & 1.3 & 1.5 & 1.0 & 0.4 \\
$70-79$ & 0.6 & 0.8 & 0.5 & 0.8 \\
$80-89$ & 0.7 & 0.6 & 0.5 & 0.2 \\
$90-99$ & - & 0.3 & 0.6 & 0.5 \\
I00+ & 1.0 & 1.3 & 0.7 & 1.2 \\
\hline Mean days & 14.0 & 14.3 & 13.0 & 12.3 \\
Standard & 23.0 & 23.4 & 20.8 & 19.1 \\
deviation & 2.0 & & \\
\hline
\end{tabular}




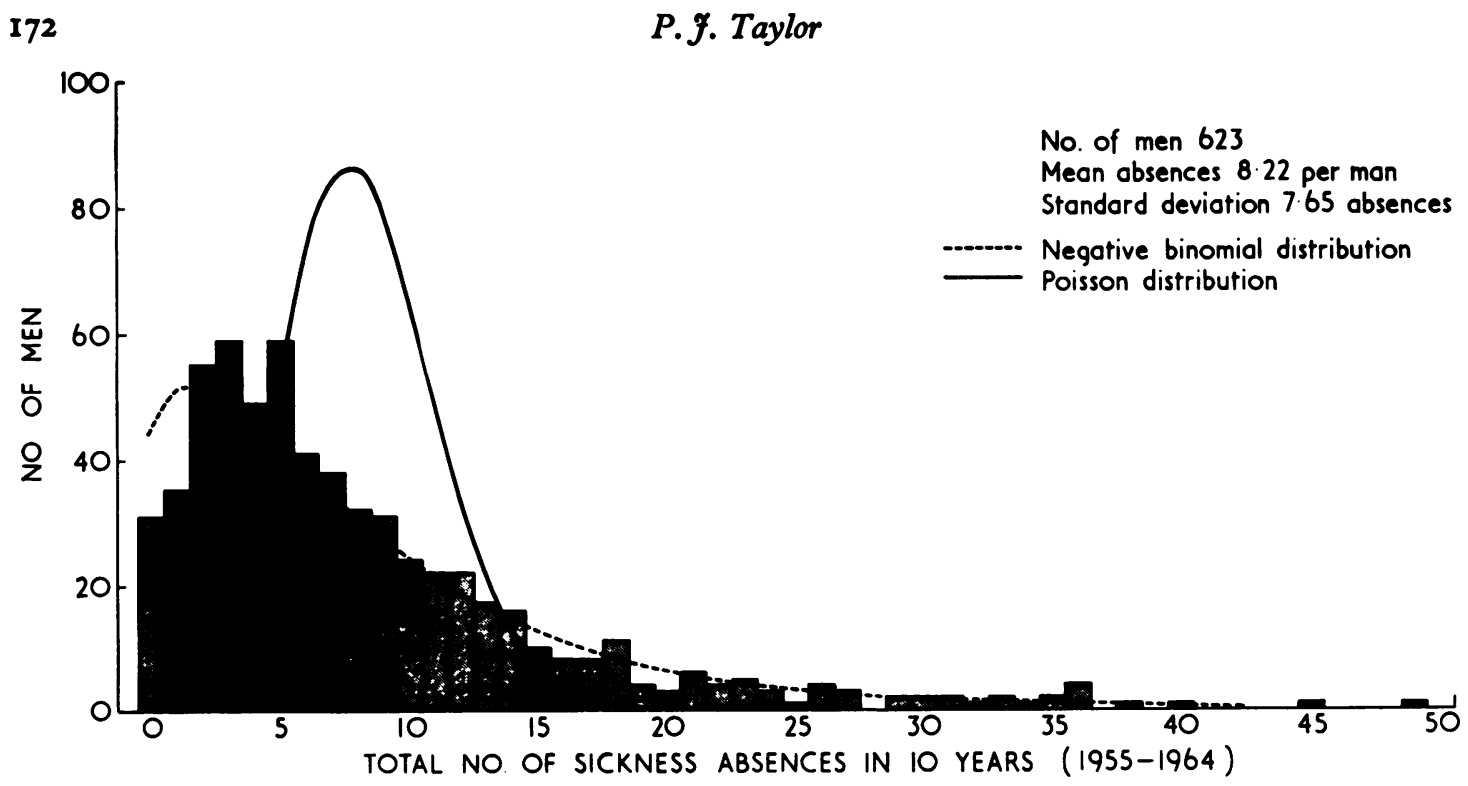

Fig. I. Number of sickness absences per man, 1955-64.

this. However, the observed differences in Tables I and II far exceed this. In the case of spells of absence, there were 60 men $(4.4 \%$ of the population) who were responsible for 335 spells $(20.3 \%$ of all spells), but with the Poisson distribution one can calculate that 60 men in the 'tail' would have $14.6 \%$ of all spells. The difference between these percentages is highly significant $(P<0.003)$. Even more marked differences can be seen in the case of total days of absence.

Since in any one year a group of men can be identified with an exceptionally high sickness absence frequency and a second group with high severity, it was considered that a third group might be found with an exceptionally low sickness absence frequency. In single years, however, about $40 \%$ of the population have no spell of absence and therefore the accumulated experience of several years was used.

The records of 623 men continuously employed from 1955 to 1964 were inspected and the number of men having $0,1,2$, etc. spells of sickness absence was noted. This distribution is shown in Fig. I together with the expected Poisson and negative binomial distributions. The resemblance to the latter distribution is reasonably close and confirms the suggestion that an unequal chance of sickness applies over longer periods than a year. The total sickness experience of the 187 men continuously employed between 1946 and 1965 showed a similar pattern with a mean of 13.03 spells per man and a standard deviation of $11 \cdot 60$, the range from 0 to 95 spells. This gives an average rate of 0.65 spell annually per man for the 20-year period, appreciably less than the 0.82 spell for the men employed for Io years. This difference can be attributed to the different age structure and length of service of the two groups since the occupational structure is similar and sick pay arrangements have remained unchanged.

A demonstration that sickness does not occur at random but resembles the negative binomial distribution does not necessarily mean that 'proneness' is involved. As Amato (quoted by Cresswell and Froggatt, 1963) showed, the distribution could be explained by a series of subgroups with differing means in the population, each normally distributed about its own mean and collected in such a way that their chance distributions are concealed in the whole.

The observations reported in this paper were made on a population of male refinery workers all having the same sick pay scheme. Approximately half the men were on continuous three-cycle shift work and, in view of the considerable difference in sickness absence already reported between these men and day workers (Taylor, 1967), the records were examined to see whether the distribution of sickness spells or days of absence differed between the two types of work. This showed for each of the four years studied that, although shift workers had 
TABLE V

Number OF Shift aNd DAY Workers having O, I, 2, ETC. SPells and 0-9, 10-19, etc. Days of Sickness AbSence IN 1964

\begin{tabular}{c|c|c||c|c|c}
\hline \multicolumn{3}{c||}{ Spells of Absence } & \multicolumn{3}{c}{ Days of Absence } \\
\cline { 1 - 2 } $\begin{array}{c}\text { No. of } \\
\text { Spells }\end{array}$ & \multicolumn{2}{c||}{ No. of Workers } & $\begin{array}{c}\text { No. of } \\
\text { Days }\end{array}$ & No. of & Workers \\
\cline { 2 - 3 } & Shift & Day & & Shift & Day \\
\hline 0 & 329 & 202 & $0-9$ & 448 & 373 \\
I & 186 & 223 & $10-19$ & 83 & 154 \\
2 & 65 & 135 & $20-29$ & 45 & 79 \\
3 & 25 & 68 & $30-39$ & 11 & 56 \\
4 & 12 & 45 & $40-49$ & 10 & 24 \\
5 & 3 & 35 & $50-59$ & 5 & 14 \\
6 & - & 16 & $60-69$ & 5 & 9 \\
7 & - & 2 & $70-79$ & 2 & 4 \\
8 & - & 3 & $80-89$ & 3 & 4 \\
9 & - & - & $90-99$ & 4 & 4 \\
I0 & - & - & $100-109$ & 1 & 4 \\
II & - & 1 & $110+$ & 3 & 5 \\
\hline Mean & & & Mean & & \\
spells & 0.73 & 1.64 & days & $9 \cdot 21$ & $16 \cdot 14$ \\
\hline
\end{tabular}

lower mean rates of sickness, both groups showed a similar pattern of distribution. The figures for one of these years are presented in Table V.

The possibility that length of service might affect the pattern was investigated by comparing men with less and more than Io years' service. It is not practicable with this relatively small population to distinguish between age and length of service. Here, too, there was a considerable difference in

TABLE VI

NUMber of Men With Less and With MORE than 10 Years' Service having $0,1,2$, etc. Spells of Sickness Absence IN 1964

\begin{tabular}{c|c|c}
\hline \multirow{2}{*}{ No. of Spells } & \multicolumn{2}{|c}{ No. of Men with } \\
\cline { 2 - 3 } & <10 Years' Service & : 10 Years' Service \\
\hline 0 & 237 & 294 \\
1 & 217 & 192 \\
2 & 118 & 82 \\
3 & 65 & 28 \\
4 & 45 & 12 \\
5 & 31 & 7 \\
6 & 13 & 3 \\
7 & 2 & - \\
8 & 2 & - \\
9 & - & - \\
10 & 1 & 0.89 \\
11 & $1 \cdot 51$ & \\
\hline Mean spells & & \\
\hline
\end{tabular}

the mean rates, long-service workers having fewer though longer spells, but the distribution of sickness within each group resembled the negative binomial form. The distribution of these men for 1964 is shown in Table VI.

Such supplementary studies, although they cannot entirely dispose of the suggestion of a number of subgroups each with a normal distribution, do suggest that such subgroups, if they exist, are not related to occupation or to length of service.

Lateness and Absenteeism An investigation of lateness and absenteeism for reasons other than sickness, holidays or union meetings has provided further evidence on this problem. An episode of

\section{TABLE VII}

Number of Men having O, I, 2, ETC. Episodes of Lateness AND 'OTHER ABSENCE' IN 1964

\begin{tabular}{|c|c|c|}
\hline No. of Episodes & $\begin{array}{l}\text { No. of Men } \\
\text { Late }\end{array}$ & $\begin{array}{c}\text { No. of Men } \\
\text { Absent }\end{array}$ \\
\hline 0 & 430 & 474 \\
\hline I & 267 & 272 \\
\hline 2 & 148 & 153 \\
\hline 3 & II9 & 115 \\
\hline 4 & 79 & 75 \\
\hline 5 & 57 & 63 \\
\hline 6 & 44 & 45 \\
\hline 7 & 29 & 34 \\
\hline 8 & 30 & 28 \\
\hline 9 & 20 & 25 \\
\hline 10 & 20 & 18 \\
\hline I I & 14 & 13 \\
\hline 12 & II & 7 \\
\hline 13 & 15 & 6 \\
\hline 14 & 8 & 3 \\
\hline 15 & 5 & 4 \\
\hline 16 & 5 & 2 \\
\hline 17 & 7 & 4 \\
\hline 18 & 7 & 2 \\
\hline I9 & 5 & 2 \\
\hline 20 & 3 & $\mathbf{T}$ \\
\hline 2 I & $\mathbf{I}$ & - \\
\hline 22 & 4 & - \\
\hline 23 & 4 & - \\
\hline 24 & 2 & - \\
\hline $25-29$ & 7 & 2 \\
\hline $30-34$ & 6 & $\mathbf{I}$ \\
\hline $35-39$ & 一 & - \\
\hline $40+$ & 3 & I \\
\hline $\begin{array}{l}\text { Mean } \\
\text { Standard deviation }\end{array}$ & $\begin{array}{l}3.35 \\
5 \cdot 35\end{array}$ & $\begin{array}{l}2.53 \\
3.76\end{array}$ \\
\hline
\end{tabular}

$\mathrm{n}=\mathbf{1}, 350$ 
lateness is recorded whenever a man 'clocks in' more than two minutes late for work and 'other absence' when he is away for the whole or part of a day. The clock cards of all men employed throughout 1964 were examined and the number of men with $0,1,2$, etc. latenesses and other absences was counted. The distribution of both forms of absenteeism closely resembles that found for sickness. The numbers of men in each group are shown in Table VII.

These findings show that episodes of both lateness and other absence are unevenly distributed in the population in a manner similar to that already described for sickness absence which is not, of course, included in either category. About one third of the men were neither absent nor late in the year, and, as with the sickness figures, there are long 'tails' of a few men having a large number of such episodes. A marked difference between the lateness and other absence records of day and shift workers has already been reported (Taylor, 1967), and, as in the case of sickness absence (Table V), the unequal chance type of distribution applies separately to both day and shift workers.

These observations, together with the other findings, raise the possibility that the negative binomial type of distribution may prove to be a characteristic of all forms of industrial absence. The pattern for 1964 is shown in Figure 2.
Secular Trends in Sickness Absence, 1964-65 As already mentioned, a well-recognized characteristic of industrial sickness absence is the fact that younger men have more frequent but shorter spells than older men. This suggests that the absence pattern of individuals changes as they become older, but only a secular study can show whether or not this assumption is true.

Although records of sickness absence have been kept at this refinery for 30 years, the abnormal conditions of life during World War II make a comparison for this period unreliable. The personal sickness record cards of the 187 men who were in continuous hourly paid employment from January $\mathrm{I}$, 1946 to December 31, I965 have been studied. Full sick pay from the first day of absence has been paid throughout this time to all men with more than six months' service.

The overall refinery sickness absence rates for this period are only available as the proportion of normal working hours lost due to sickness and injury (percentage time lost), since measures such as the inception rate (spells) have only been used since 1955. The sickness trend has been upwards over this period to a peak in 1963, and the annual percentage time lost rates are shown in Table VIII.

It is against this background of a gradually rising sickness absence rate that the changes in individuals must be seen.

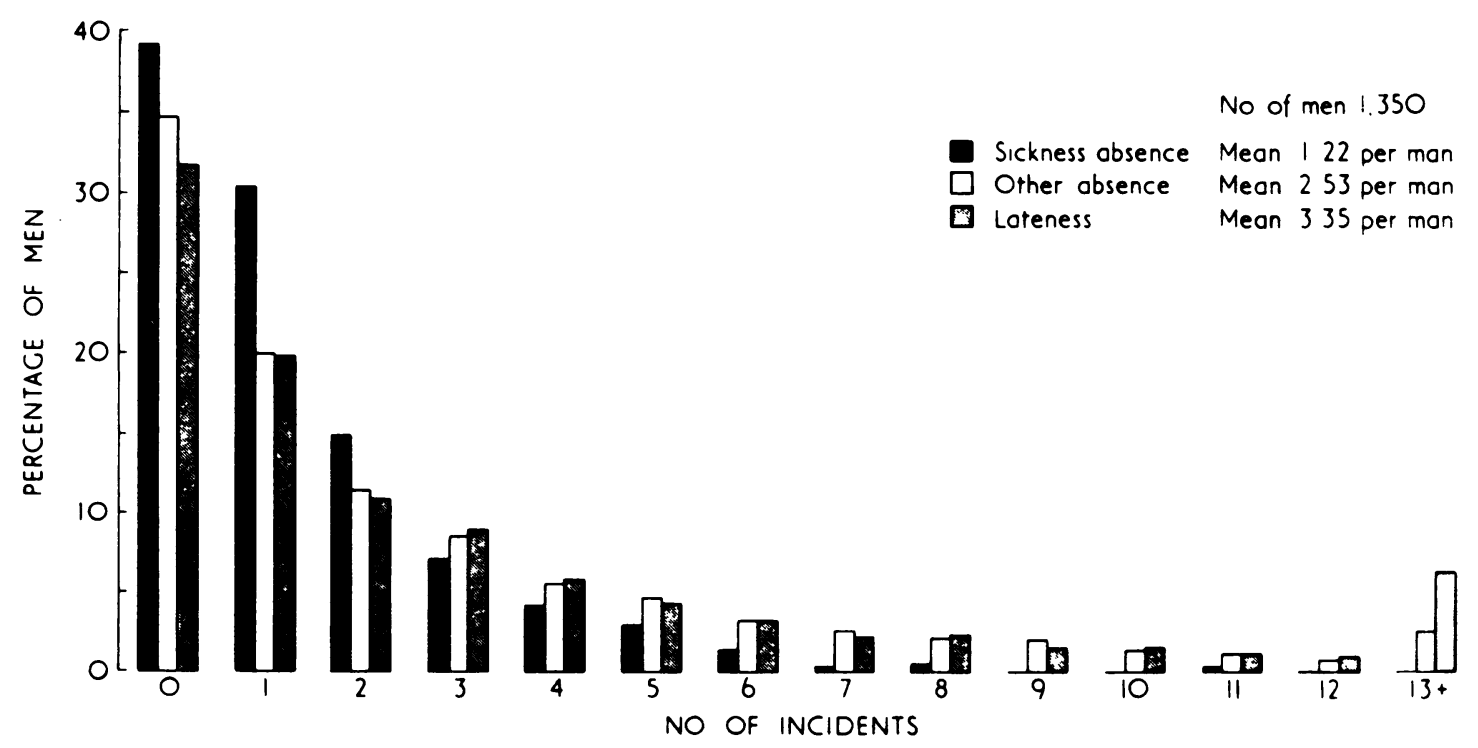

FIG. 2. Sickness absence, lateness, and other absences, 1964 . 
TABLE VIII

Percentage Time Lost due to Sickness Absence in ali Male Hourly-Paid EMPloyees, 1946-65

\begin{tabular}{c|c||c|c}
\hline Year & Percentage & Year & Percentage \\
\cline { 1 - 2 } 1946 & 2.51 & 1956 & 3.65 \\
1947 & 2.87 & 1957 & 3.96 \\
1948 & 2.60 & 1958 & 3.12 \\
1949 & 2.97 & 1959 & 3.27 \\
1950 & 2.92 & 1960 & 3.54 \\
& & & \\
1951 & 2.93 & 1961 & 4.08 \\
1952 & 2.92 & 1962 & 4.33 \\
1953 & 3.31 & 1963 & 4.53 \\
1954 & 2.73 & 1964 & 3.89 \\
1955 & 3.29 & 1965 & 3.57 \\
\hline
\end{tabular}

Three methods of comparison have been used for this study - the number of sickness spells sustained by each man during the 20 years, the inception rate (spells) of the group, and also the inception rate (persons).

The number of sickness spells for each man in successive five-year periods was compared. The majority (135 men) showed no consistent trend either way, 31 men $\left(17^{\circ}\right)$ showed a consistent rise, and 21 men ( $1 \mathrm{I}^{\circ}$ ) showed a fall in the number of spells. When the trend was compared for two ro-year periods, 95 men had more spells in the second 10 years, 73 had less, and 19 showed no change. On a $2 \times 2$ table the difference in the two Io-year periods is not statistically significant (0.05 $<\mathrm{P}<0.10)$.

When measuring group sickness rates the age range should be considered. The ages of the 187 men in 1946 ranged from 18 to 40 years since men retire at this refinery at the age of 60 years. In view of the recognized difference in sickness absence of young and old, the men were divided into two groups-those under 30 years of age in 1946 ( 66 men) and those over 30 (I2I men). With such relatively small numbers, the sickness rates have been calculated for four periods of five years, thus producing for the younger men a population at risk of 330 man-years for each of the four periods.

The mean annual inception rates (spells) for each of these five-year periods in both groups of men are shown in Table IX.

Two points emerge from this table. First, younger men had a higher mean rate than the older men in three out of the four periods, the wellrecognized characteristic already mentioned. Secondly, there is no consistent fall in rate in either group with the passage of time.

The third method of comparison uses the
TABLE IX

Mean ANNuAl Inception Rates (SPells) For 187 Men, 1946-65

\begin{tabular}{|c|c|c|c|c|c|}
\hline \multirow{2}{*}{$\begin{array}{c}\text { Group } \\
\text { Age in } \\
\text { I946 }\end{array}$} & \multicolumn{5}{|c|}{ Inception Rate (Spells) per roo Men } \\
\hline & $1946-50$ & $1951-55$ & $1956-60$ & $1961-65$ & Mean \\
\hline $\begin{array}{l}18-29 \\
30-40\end{array}$ & $\begin{array}{l}50 \cdot 0 \\
52.4\end{array}$ & $\begin{array}{l}89 \cdot 1 \\
62 \cdot 6\end{array}$ & $\begin{array}{l}67.6 \\
66.3\end{array}$ & $\begin{array}{l}75.5 \\
67.8\end{array}$ & $\begin{array}{l}70 \cdot 6 \\
62 \cdot 3\end{array}$ \\
\hline All men & $51 \cdot 6$ & $72 \cdot 0$ & $66 \cdot 7$ & $71 \cdot 0$ & $65 \cdot 3$ \\
\hline
\end{tabular}

inception rate (persons) for these five-year periods. This rate measures the number of men having at least one spell of sickness absence during a year but does not count the number of spells. This method of measurement is the one used by the Ministry of Social Security, and in the extensive survey of regional and occupational sickness absence (Ministry of Pensions and National Insurance, 1965) it was shown that the highest rates are found in men over 55 and under 24 years of age, and the lowest rate in the age group 35-44 years. These rates for the 187 men studied are presented in Table X.

TABLE X

Mean annual Inception Rates (Persons) for 187 Men, 1946-65

\begin{tabular}{|c|c|c|c|c|c|}
\hline \multirow{2}{*}{$\begin{array}{c}\text { Group } \\
\text { Age in } \\
1946\end{array}$} & \multicolumn{5}{|c|}{ Inception Rate (Persons) fer $100 \mathrm{Men}$} \\
\hline & $1946-50$ & $1951-55$ & $1956-60$ & $1961-65$ & Mean \\
\hline $\begin{array}{l}18-29 \\
30-40\end{array}$ & $\begin{array}{l}34 \cdot 6 \\
36 \cdot I\end{array}$ & $\begin{array}{l}52.7 \\
39.5\end{array}$ & $\begin{array}{l}47 \cdot 3 \\
43 \cdot 3\end{array}$ & $\begin{array}{l}49 \cdot 1 \\
44 \cdot 6\end{array}$ & $\begin{array}{l}45.9 \\
40.9\end{array}$ \\
\hline All men & $35 \cdot 5$ & $44 \cdot 2$ & $44 \cdot 7$ & $46 \cdot 2$ & $42 \cdot 2$ \\
\hline
\end{tabular}

From the national rates referred to above one might expect that the younger men would show a fall in the rates over the 20 years and the older men a rise. The figures in Table $X$ show a slight rise in both groups, more marked in the younger men. Since this rate is based on the number of men and not on the number of spells the use of a Chi-square test is acceptable with the correction for continuity by the use of Yates' factor. On the null hypothesis that the same number of men should have an episode of sickness absence in each five-year period, the difference in the younger men is significant $\left(\chi^{2}=12.95, \mathrm{n}=3, \mathrm{P}-0.01\right)$, but the difference in the older men is not $\left(\chi^{2}=6 \cdot 26, n=3, P \cdot O \cdot I\right)$. 


\section{Discussion}

All three related methods of measuring the change in sickness absence over the 20-year period show that the frequency of spells has not fallen. This is in contrast with the impression received when age-related rates are presented for a single period in time.

There are two explanations for this apparent paradox, both of which should be considered. First, there has been a rise in sickness rates in this country in the past 20 years (Morris, 1965), which also applied to this refinery (Table VIII), although there has been a consistent fall recently and the time lost in 1966 fell to $3.27 \%$. Raffle (1966) has shown that the rise in sickness spells has been most marked in men under 44 years of age, whereas the rates in older men have scarcely changed. This national rise would tend to cancel out any fall that might be expected from ageing. Secondly, all industrial populations are 'survivor populations' (Reid, 1957); not only do men select themselves to enter any particular employment, but they are free to resign or to transfer to other occupations. A high mean rate of sickness absence in young men might be caused in part by a few who do not remain in the same employment.

The present study has provided some evidence that this is the case since the younger men who in the last two years of the period were aged 38-49 had an annual inception rate (spells) of 8I per 100 men whereas all employees of that age had a rate of I 6 spells per 100 men. Similarly, the older group of men then aged 50-59 had a rate of 78 spells per 100 men compared with 82 spells per 100 men for all employees of the same age. Such differences tend to confirm the suggestion that men with long service have low rates of sickness.

Evidence that men who leave the company have had more sickness absence than men who do not comes from an inspection of the records of men who resigned in 1965 . They all left for personal reasons and none was encouraged to do so because of a bad sickness record. Their ages ranged from 19 to 44 years and their sickness records in the two preceding years had been compared with those of a control group of men who did not resign, matched for age, occupation, and hours of work. The results are shown in Table XI.

A final point for consideration is the effect that a change of occupation can make on a man's sickness record. Job dissatisfaction is known to be an important factor in the causation of sickness absence and of short spells in particular (Bashford, 1944; Walker and Marriott, I95I; Heron, 1955; Taylor,

\section{TABLE XI}

Sickness Absence Spells in 1963 AND 1964 OF MEN Who REsigned IN 1965 AND OF A MATChED CONTROL Group OF MEN WHO DID NOT RESIGN

\begin{tabular}{l|c|c|c}
\hline Group & No. of Men & $\begin{array}{c}\text { No. of Spells } \\
\text { in } \\
1963 \text { and 1964 }\end{array}$ & $\begin{array}{c}\text { Mean Annual } \\
\text { Spells per } \\
\text { I00 Men }\end{array}$ \\
\hline Resigned & 33 & 105 & 159 \\
Controls & 33 & 79 & 120 \\
\hline
\end{tabular}

1966). In large organizations it is sometimes possible for a man to change his job without leaving the company. This occurs at this refinery, particularly in men without a craft skill. In a number of instances such a change has been associated with a dramatic improvement in the man's sickness record. Sixteen such examples have been observed in the past few years at this refinery, and the two summarized below illustrate the point.

M.S. was born in 1941. He was first employed as a day-work gas bottle filler on February I, 1960 and was transferred to the lubricating oil unit in March 1964. He changed to three-cycle shift work in June 1964. Sickness record: $1960-3$ spells, 27 days; $1961-2$ spells, 18 days; 1962-3 spells, I 3 days; 1963-8 spells, 19 days; $1964-I$ spell, I day; $1965-$ I spell, 5 days; 1966-no spells.

M.C. was born in 1942. He was first employed as a day-work labourer on March 20, I96I and was transferred to the job of craftsman's mate in May 1962. He changed to three-cycle shift work in February 1964. Sickness record: $196 \mathrm{I}-1$ spell, I5 days; $1962-8$ spells, 32 days; $1963-4$ spells, 28 days; $1964-2$ spells, 4 days; I965-I spell, 2 days; I966-no spells.

Although such cases are relatively uncommon their effect on overall sickness rates is the same as if a man with a bad sickness record left the company and was replaced by another with a good record. Such changes usually occur in the first few years of employment.

It therefore appears that the paradox noted at the beginning of this section is explicable by the combination of a rising national trend in sickness absence together with a greater labour turnover among the younger men with a high frequency of sickness absence.

I would like to thank Dr. W. H. Hargreaves for helpful criticism in preparing this paper. Some of the material formed part of a thesis approved by the University of London for the degree of M.D. 


\section{REFERENCES}

Arbous, A. G., and Kerrich, J. E. (1951). Biometrics, 7, 340. Bashford, H. H. (1944). Brit. F. industr. Med., 1, 7.

Cresswell, W. L., and Froggatt, P. (1963). The Causation of Bus Driver Accidents. Oxford University Press, London.

Froggatt, P., and Smiley, J. A. (1964). Brit. F. industr. Med., 2I, $I$.

Greenwood, M., and Woods, H. M. (1919). Rep. industr. Fatigue Res. Bd, No. 4. H.M.S.O., London.

Health of Munitions Workers Committee. (1917). Efficiency and Fatigue. London.

- (1918). Final Report, London.

Heron, A. (1955). Brit. F. industr. Med., 12, 322.

Hinkle, L. E., and Wolff, H. G. (1957). Arch. intern. Med., 99, 442.

Jones, G. M. (1959). Brit. F. prev. soc. Med., 13, 74.
London Transport Executive (1956). Health in Industry. Butterworth, London.

Ministry of Pensions and National Insurance. (1965). Report on an Enquiry into the Incidence of Incapacity for Work, Part II. H.M.S.O., London.

Morris, J. N. (1965). Proc. roy. Soc. Med., 58, 821.

Raffle, P. A. B. (1966). F. Inst. Actuaries Stud. Soc., 18, 71.

Reid, D. D. (1957). Roy. Soc. Hlth F., 77, 675.

Russell, W. T., Whitwell, G. P. B., and Ryle, J. A. (1947). Brit. F. industr. Med., 4, 56.

Shepherd, R. D., and Walker, J. (I957). Ibid., I4, 266.

Sutherland, I., and Whitwell, G. P. B. (1948). Ibid., 5, 77

Taylor, P. J. (1966). M.D. Thesis, University of London. (1967). Brit. F. industr. Med., 24, 93.

Walker, J., and Marriott, R. (195I). Occup. Psychol., 25, 181.

Wyatt, S. (1945). A Study of Certified Sickness Absence among Women in Industry. Rep. industr. Hlth, Res. $B d$, No. 86. H.M.S.O., London. 